\title{
Dispersion kinetics in mechanically agitated vessel
}

\author{
Elia Bucciarelli ${ }^{1,2}$, Roman Formánek ${ }^{2}$, Bohuš Kysela ${ }^{3}$, Ivan Fořt ${ }^{2}$, and Radek Šulc ${ }^{*}$ \\ ${ }^{1}$ University of Bologna, Department of Civil, Chemical, Environmental, and Materials Engineering, Via Terracini 28, Bologna, Italy \\ ${ }^{2}$ Czech Technical University in Prague, Faculty of Mechanical Engineering, Department of Process Engineering, Technická 4, 16607 \\ Prague, Czech Republic \\ ${ }^{3}$ Czech Academy of Sciences, Institute of Hydrodynamics v.v.i, Pod Patankou 30/5, 16612 Prague, Czech Republic
}

\begin{abstract}
Agitation of two immiscible liquids or solid-liquid suspension is a frequent operation in chemical and metallurgical industries. Prediction of mean drop/particle size and drop/particle size distribution (DSD) is vital for emulsification, suspension polymerization, solid particle dispersion or crystallization. Simulation of particulate systems requires the knowledge of DSD and its time evolution. The time evolution of drop size distribution was investigated in baffled vessel mechanically agitated by a Rushton turbine and a high-shear tooth impeller. The system water-silicone oil was used as a model liquid. The volume fraction of the dispersed phase was $0.047 \%$. The drop sizes were determined by image analysis. The time evolution of the drops size $d_{p 32}$ was studied for both impellers tested. The model used involves the first order kinetics. Finally, the following correlations predicted by the Kolmogorov-Hinze theory were evaluated at steady state: $d_{p 32} / D=C_{1} . W e^{-0.6}$ and $d_{p \max } / D=\mathrm{C}_{2} . W e^{-0.6}$, where $W e$ is the impeller Weber number.
\end{abstract}

\section{Introduction}

Agitation of two immiscible liquids or solid-liquid suspension is a frequent operation in chemical and metallurgical industries. As an example it can serve suspension/emulsion polymerization, heterogeneous /phase-transfer catalytic chemical reaction and hydrometallurgical solvent extraction. Mixing plays a crucial role in these technologies, because it intensifies blending, homogenization, mass transfer and chemical reactions etc. The product quality, yield and economy of the processes are hence significantly affected by mixing. Insufficient or excessive mixing may lead to wastage of processing time and raw materials and/or the formation of by-products [1,2]. Prediction of mean drop/particle size and drop/particle size distribution (DSD) is vital for emulsification, suspension polymerization, solid particle dispersion or crystallization. Simulation of particulate systems requires the knowledge of DSD and its time evolution. Such description is rare in the literature.

The aim of this contribution is to investigate the time evolution of drop size distribution in baffled vessel mechanically agitated by a Rushton turbine and a highshear tooth impeller. The drop size will be determined by an image analysis. The system water -silicone oil was used as a model liquid. The procedure proposed for image analysis was tested and calibrated using special monodisperse spherical particles having diameter of 1.19 $\mathrm{mm}$. In a subsequent analysis the minimum number of drops necessary to obtain relevant data was evaluated for each speed of the impeller.

\section{Theoretical background}

The time evolution of Sauter mean diameter $d_{p 32}$ of droplets was described by the first-order kinetic model proposed by Šulc et al. [3]:

$$
-\frac{d\left(d_{p}\right)}{d t}=k \cdot\left(d_{p}-d_{p f}\right)
$$

where $k$ is the breaking rate-constant, $d_{p}$ is the actual drop size in time $t$, and $d_{p f}$ is the final drop size. Integrating Eq. (1) for the initial condition $d_{p}(t=0)=$ $d_{p 0}$ and taking a number of passages of liquid through an impeller into account the following time dependency of drop size $d_{p}$ can be obtained in dimensionless form as follows

$$
d_{p}^{*}=\frac{d_{p}-d_{p f}}{d_{p 0}-d_{p f}}=\exp (-k \cdot t)=\exp \left(-k^{*} \cdot t^{*}\right)
$$

where $k^{*}$ is the dimensionless breaking rate-constant $\left(k^{*}=k / N\right), d_{p}{ }^{*}$ is the dimensionless drop size, $t^{*}$ is the dimensionless time $\left(t^{*}=N . t\right)$, and $N$ is the impeller rotational speed. This model was proposed on the basis of following assumptions: 1) the breaking occurs during passage through the impeller only, 2) broken drops do not re-aggregate again, and 3) drop breaking occurs in a mechanically agitated vessel in the inertial subrange.

\footnotetext{
$\overline{{ }^{*} \text { Corresponding author: radek.sulc@fs.cvut.cz }}$
} 


\section{Experimental}

The time evolution of drop size distribution was investigated in baffled vessel mechanically agitated by a Rushton turbine and high-shear tooth impeller (CVS 691038.1). The system water - silicone oil was used as a model liquid. The volume fraction of the dispersed phase was $0.047 \%$. The drop sizes were determined by image analysis.

\subsection{Experimental apparatus}

The dispersion experiments were conducted in a fully baffled cylindrical vessel of inner diameter $T=300 \mathrm{~mm}$ with flat bottom and 4 baffles per $90^{\circ}$, filled in height $H$ $=T$. The impeller of diameter $D=100 \mathrm{~mm}$ was placed at an off-bottom clearance of $C / D=0.85$. The baffle width $B / T$ was 0.1 . The impeller motor and speed control unit IKAŇEUROSTAR POWER control-visc was used in our experiments. The impeller speed was set up and the value of impeller power input was calculated using impeller power characteristics.

\subsection{Image analysis technique}

The drop sizes were determined using non-intrusive optical method. The method is based on an analysis of images obtained by digital camera in a plane illuminated by a light. The method consists of three steps: 1) illumination of a plane in the tank with a light sheet in order to visualize the drops, 2) record of the images of the drops using a camera, 3) processing of the images captured by image analysis software. In this case the backlight illumination was used that ensured the best image quality. To reduce an image distortion the agitated vessel was placed into an optical box (water filled rectangular box). The investigated area was located 40 $\mathrm{mm}$ from impeller axis and its off-bottom clearance was $75 \mathrm{~mm}$. The focused plane was approximately $50 \mathrm{~mm}$ from vessel wall. This place was chosen according to the circulation loop shape generated by the radial impeller.
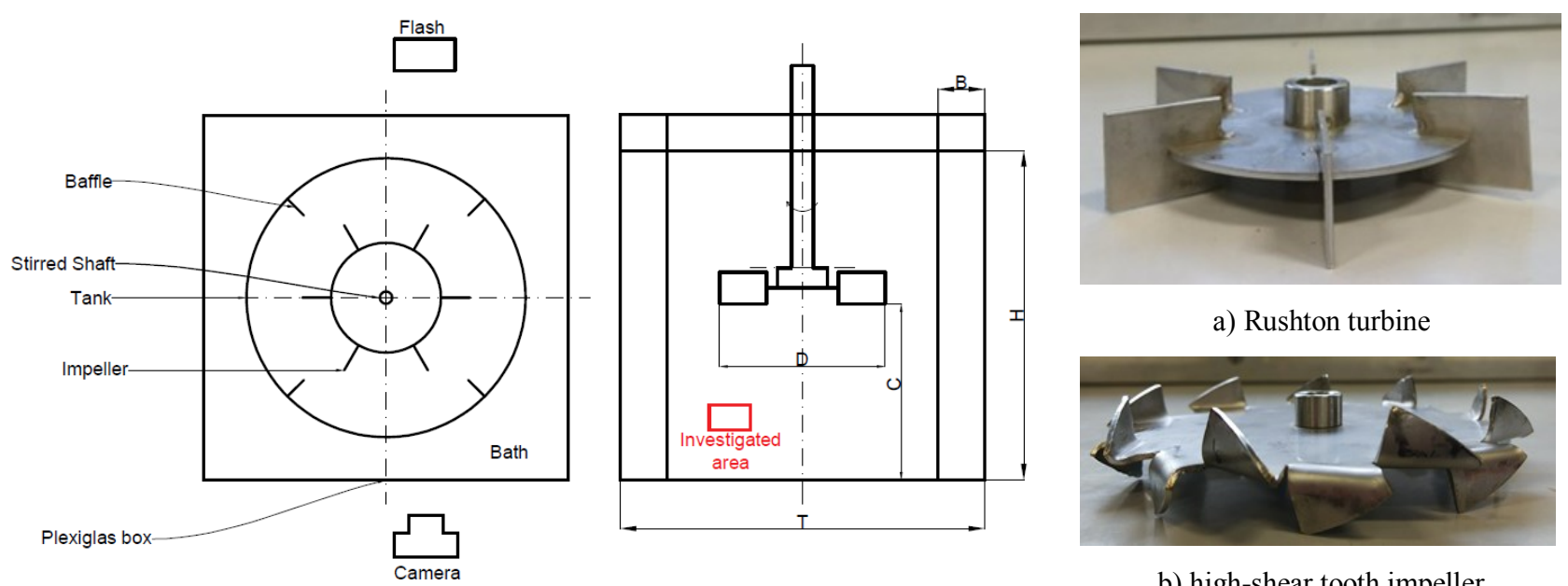

a) Rushton turbine

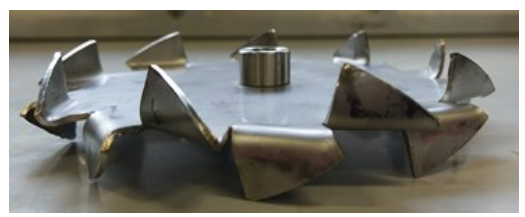

b) high-shear tooth impeller

Fig. 1. Schema of experimental apparatus for image analysis. 
4. Image acquisition: After impeller speed jump the drops are breaking. During drop breaking the images of drops passing through the focused plane illuminated by backlight were captured with frame rate $30 \mathrm{~s}^{-1}$ and shutter time $0.1 \mathrm{~ms}$. The camera resolution was $1280 \mathrm{x}$ 1024 pixels. The image capturing takes approx. $33 \mathrm{~s}$. Finally approx. 1000 images were obtained for given capturing run and ones were stored into a hard disk as 8bit tiff format.

5. Image analysis: From images captured, the drops were identified and their equivalent drop diameter calculated according to projected area was determined for given stirring time. The images were analyzed using ImageJ software and its pre-defined filters and our macros [4]. In a subsequent analysis the minimum number of drops necessary to obtain relevant data was evaluated for each speed of the impeller.

Table 2. Physical properties of immiscible liquid-liquid system

\begin{tabular}{|c|c|c|}
\hline & Continuous phase & Dispersed phase \\
\hline & Water & $\begin{array}{c}\text { Silicone oil } \\
\text { WACKER AP 200 }\end{array}$ \\
\hline$\rho\left(\mathrm{kg} / \mathrm{m}^{3}\right)$ & 998 & 1070 \\
\hline$\mu(\mathrm{Pa} . \mathrm{s})$ & $0.955 \times 10^{-3}$ & $0.214 \times 10^{-3}$ \\
\hline$\varphi(\mathrm{v} / \mathrm{v})$ & $\mathrm{x}$ & 0.00047 \\
\hline$\sigma(\mathrm{N} / \mathrm{m})$ & $7.2 \times 10^{-2}$ & $3.5 \times 10^{-2}$ \\
\hline
\end{tabular}

Table 3. Experimental conditions

\begin{tabular}{|c|c|c|}
\hline & \multicolumn{2}{|c|}{$N_{\text {starting }} \rightarrow N_{\text {desired }}(\mathrm{rev} / \mathrm{min})$} \\
\hline Run \# & Rushton turbine & Tooth impeller \\
\hline 1 & $150 \rightarrow 200$ & $400 \rightarrow 450$ \\
\hline 2 & $200 \rightarrow 250$ & $450 \rightarrow 500$ \\
\hline 3 & $250 \rightarrow 300$ & $500 \rightarrow 550$ \\
\hline 4 & $300 \rightarrow 350$ & $550 \rightarrow 600$ \\
\hline 5 & $350 \rightarrow 400$ & $\mathrm{xxx}$ \\
\hline
\end{tabular}

\section{Data analysis}

\subsection{Calibration test}

To obtain the ratio between the real dimensions of the particles and the pixels detected by image analysis the calibration tests were carried out. For calibration the special polymeric spheres "Nylon 6/6 Balls" of precise diameter of $3 / 64$ " $=1.19 \mathrm{~mm}$ were used. The photo of these calibration spheres is presented in Figure 2.

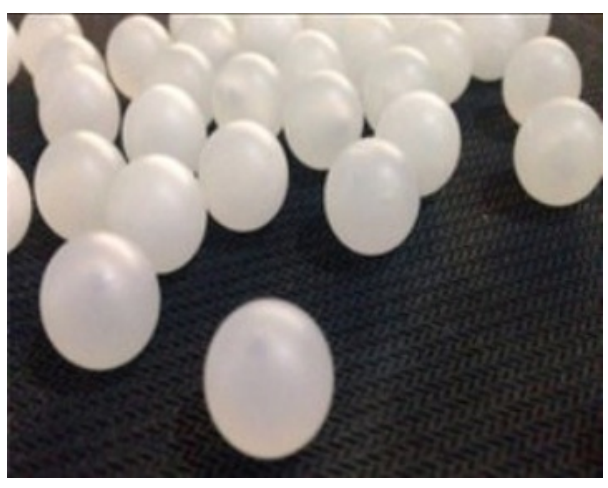

Fig. 2. The precise calibration spheres "Nylon 6/6 Balls".
The calibration tests were performed always in the same way: 1000 images captured in 33.3 seconds at a given impeller rotational speed for both tested impellers. For image analysis only the high-quality images were taken into account. For illustration, two images of various quality are presented in Figure 3 in order to highlight the differences between an acceptable image (Fig. 3b) which is therefore suitable for subsequent processing and a discarded image (Fig. 3a). The image resolution for this test was $0.01479 \mathrm{~mm} / \mathrm{pixel}$.

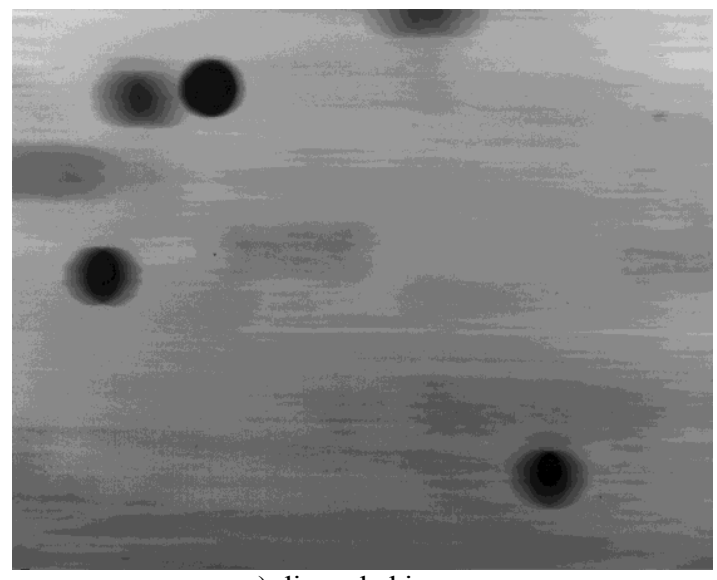

a) discarded image

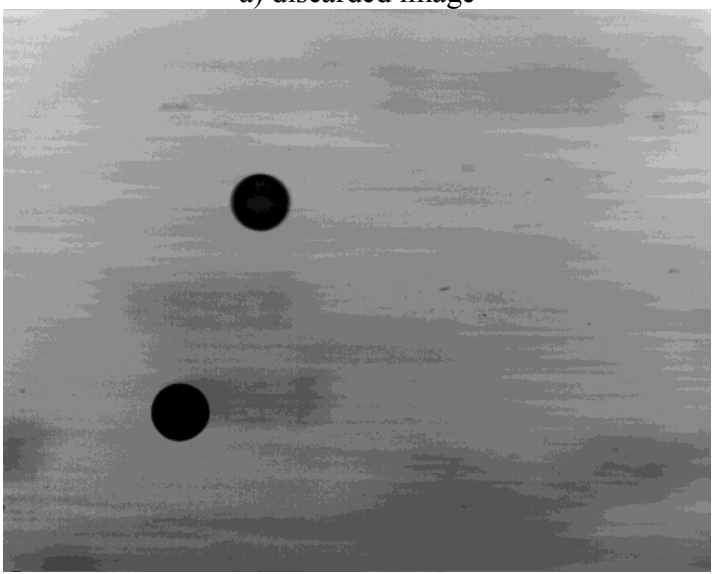

b) high quality image

Fig. 3. Image analysis: quality of captured images.

\subsubsection{Calibration results for Rushton turbine}

The three calibration tests were performed for three various impeller rotational speeds of Rushton turbine. The size distribution of calibration particles evaluated by the image analysis is presented in Table 4 for each impeller speed. The total number of identified particles was 156,131 and 131 for $200 \mathrm{rpm}, 300 \mathrm{rpm}$ and $400 \mathrm{rpm}$ respectively. Then, the weighted average was calculated for each impeller speed. As it follows from Table 4, the size of calibration particles treated by the used image analysis procedure is around $1.3 \mathrm{~mm}$, i.e. the diameters identified by the used image analysis procedure were higher than the declared diameter of calibration particles. The corresponding correction coefficient was used for recalibration of drop diameters identified during experimental runs. We assume that the correction coefficient remains the same regardless of drop size. 
Table 4. Calibration data results for Rushton turbine

\begin{tabular}{|c|c|c|c|c|}
\hline $\begin{array}{c}\text { Calib. } \\
\text { test }\end{array}$ & $\begin{array}{c}\text { Impeller } \\
\text { speed } \\
N[\mathrm{rpm}]\end{array}$ & $\begin{array}{c}\text { Range } \\
\text { diameter } \\
{[\mathrm{mm}]}\end{array}$ & $\begin{array}{c}\text { Relative } \\
\text { count } \\
{[\%]} \\
\end{array}$ & $\begin{array}{c}\text { Weighted } \\
\text { average } \\
{[\mathrm{mm}]}\end{array}$ \\
\hline \multirow{4}{*}{1} & \multirow{4}{*}{200} & $<1.260$ & 0.64 & \multirow{4}{*}{$\begin{array}{c}1.301 \pm \\
0.034\end{array}$} \\
\hline & & $1.260 \div 1.286$ & 17.31 & \\
\hline & & $1.286 \div 1.311$ & 53.21 & \\
\hline & & $1.311 \div 1.337$ & 28.85 & \\
\hline \multirow{4}{*}{2} & \multirow{4}{*}{300} & $<1.255$ & 0.76 & \multirow{4}{*}{$\begin{array}{c}1.294 \\
\pm 0.035\end{array}$} \\
\hline & & $1.255 \div 1.285$ & 30.53 & \\
\hline & & $1.285 \div 1.316$ & 60.31 & \\
\hline & & $1.316 \div 1.347$ & 8.40 & \\
\hline \multirow{4}{*}{3} & \multirow{4}{*}{400} & $<1.245$ & 0.76 & \multirow{4}{*}{$\begin{array}{c}1.292 \\
\pm 0.040\end{array}$} \\
\hline & & $1.245 \div 1.276$ & 20.61 & \\
\hline & & $1.276 \div 1.307$ & 56.49 & \\
\hline & & $1.307 \div 1.338$ & 22.14 & \\
\hline
\end{tabular}

\subsubsection{Calibration results for high-shear tooth impeller}

The two calibration tests were performed for two various impeller rotational speeds of high-shear tooth impeller. The size distribution of calibration particles evaluated by the image analysis is presented in Table 5 for each impeller speed. The total number of identified particles was 35 and 33 for $400 \mathrm{rpm}$ and $500 \mathrm{rpm}$ respectively. Then, the weighted average was calculated for each impeller speed. As it follows from Table 5, the size of calibration particles treated by the used image analysis procedure is around $1.37 \mathrm{~mm}$, i.e. the diameters identified by the used image analysis procedure were higher comparing with results obtained for Rushton turbine.

Table 5. Calibration data results for high-shear tooth impeller

\begin{tabular}{|c|c|c|c|c|}
\hline $\begin{array}{c}\text { Calib. } \\
\text { test }\end{array}$ & $\begin{array}{c}\text { Impeller } \\
\text { speed } \\
N \text { [rpm] }\end{array}$ & $\begin{array}{c}\text { Range } \\
\text { diameter } \\
{[\mathrm{mm}]}\end{array}$ & $\begin{array}{c}\text { Relative } \\
\text { count } \\
{[\%]}\end{array}$ & $\begin{array}{c}\text { Weighted } \\
\text { average } \\
{[\mathrm{mm}]}\end{array}$ \\
\hline \multirow{4}{*}{1} & \multirow{4}{*}{400} & $<1.347$ & 2.86 & \multirow{4}{*}{$\begin{array}{c}1.366 \\
\pm 0.030\end{array}$} \\
\hline & & $1.347 \div 1.363$ & 45.71 & \\
\hline & & $1.363 \div 1.379$ & 34.29 & \\
\hline & & $1.379 \div 1.395$ & 17.14 & \\
\hline \multirow{4}{*}{2} & \multirow{4}{*}{500} & $<1.344$ & 3.03 & \multirow{4}{*}{$\begin{array}{c}1.366 \\
\pm 0.028\end{array}$} \\
\hline & & $1.344 \div 1.360$ & 24.24 & \\
\hline & & $1.360 \div 1.375$ & 51.52 & \\
\hline & & $1.375 \div 1.391$ & 21.21 & \\
\hline
\end{tabular}

\subsection{Minimum number of drops for evaluation}

The question arises which minimum number of drops is necessary to evaluate to obtain relevant data. The principle of this analysis is following: the mean diameter was calculated for increasing number of drops, i.e. 1000, 2000 etc.. The number of drops for which the mean diameter start to be constant was assumed to be the minimum number of drops that is necessary for treatment. For illustration, the course of mean diameter in dependence on number of drops used for averaging is presented in Fig. 4. The minimum number of drops that is necessary to evaluate was determined for each impeller rotational speed for both impellers. The determined values are presented in Table 6.

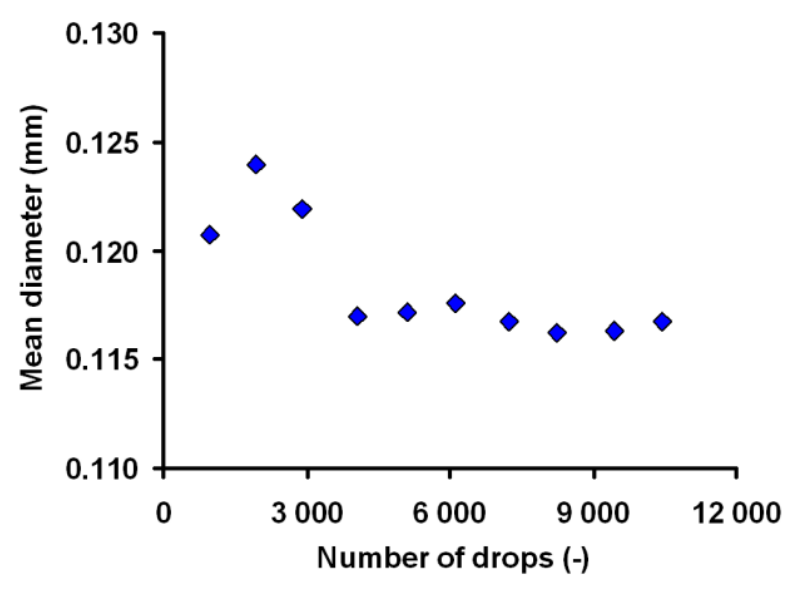

Fig. 4. Determination of minimum number of drops - principle (Rushton turbine, $\mathrm{N}=150 \mathrm{rpm}$ ).

Table 6. Minimum number of drops for evaluation - effect of impeller rotational speed

\begin{tabular}{|c|c|c|}
\hline & \multicolumn{2}{|c|}{ Minimum number of drops [-] } \\
\hline $\begin{array}{c}\text { Impeller speed } \\
N[\mathrm{rpm}]\end{array}$ & Rushton turbine & Tooth impeller \\
\hline 150 & 4070 & $\mathrm{xxx}$ \\
\hline 200 & 3415 & $\mathrm{xxx}$ \\
\hline 250 & 3019 & $\mathrm{xxx}$ \\
\hline 300 & 4652 & $\mathrm{xxx}$ \\
\hline 350 & 5019 & $\mathrm{xxx}$ \\
\hline 400 & 3817 & 1572 \\
\hline 450 & $\mathrm{xxx}$ & 1911 \\
\hline 500 & $\mathrm{xxx}$ & 1967 \\
\hline 550 & $\mathrm{xxx}$ & 1855 \\
\hline 600 & $\mathrm{xxx}$ & 1830 \\
\hline
\end{tabular}

The effect of the impeller rotational speed $N$ on the minimum number of drops was tested by hypothesis testing [5] for both impellers tested. The statistical method of hypothesis testing can estimate whether the differences between the predicted parameter values (e.g. according to some proposed theory) and whether the parameter values evaluated from the measured data are negligible. In this case, we assumed dependence of the minimum number of drops on the impeller rotational speed, described by the simple power law correlation, minimum number of drops $=B_{R} .(N)^{\beta \text { calc }}$, and then the difference between predicted exponent $\beta_{\text {pred }}$ and evaluated exponent $\beta_{\text {calc }}$ was tested. The hypothesis test characteristics are given as $t=\left(\beta_{\text {calc }}-\beta_{\text {pred }}\right) / s_{\beta}$ where $s_{\beta}$ is the standard error of parameter $\beta_{\text {calc }}$. If the calculated $|t|$ value is less than the critical value of the t-distribution for $(m-2)$ degrees of freedom and significance level $\alpha$, the difference between $\beta_{\text {calc }}$ and $\beta_{\text {pred }}$ is statistically negligible (statisticians state: "the hypothesis cannot be rejected"). In our case, the independence of minimum number of drops from the impeller rotational speed was tested as the hypothesis, i.e. minimum number of drops $=$ $B_{H} .(N)^{0}=$ const., i.e. $\beta_{\text {pred }}=0$. The hypothesis test results are presented in Table 7. For illustration, the values of calculated $|t|$ value are presented here also. The critical tdistribution coefficient $t_{(m-2), \alpha}$ for significance level $\alpha=$ 
0.05 is 2.7764 and 3.1825 for Rushton turbine and highshear tooth impeller respectively. On the basis of the results of this hypothesis test, minimum number of drops can be statistically taken as constant and independent of the impeller rotational speed for both impellers tested. Thus, the minimum number of drops was calculated as the average of the data obtained and then reported in Table 7. It has been found that the minimum number of drops that must be treated to obtain relevant data is 3999 and 1827 for Rushton turbine and high-shear tooth impeller respectively.

Table 7. Minimum number of drops for evaluation hypothesis testing

\begin{tabular}{|l|c|c|}
\hline \multicolumn{1}{|c|}{ Hypothesis testing } & $\begin{array}{c}\text { Rushton } \\
\text { turbine }\end{array}$ & $\begin{array}{c}\text { High-shear } \\
\text { tooth impeller }\end{array}$ \\
\hline & & \\
\hline Relation: $\beta_{\text {calc }}(-)$ & 0.168 & 0.296 \\
Hypothesis: $\beta_{\text {pred }}(-)$ & 0 & 0 \\
t-characteristics $|t|$ & 0.7 & 1.1 \\
Critical t-characteristics & 2.7764 & 3.1825 \\
Hypothesis: & acceptable & acceptable \\
\hline Average value & 3999 & 1827 \\
\hline
\end{tabular}

Note: Hypothesis testing: number of drops $=B_{R} \cdot(\mathrm{N})^{\text {Bcalc }}$, hypothesis tested: number of drops $=\mathrm{B}_{\mathrm{H}} \cdot(\mathrm{N})^{0}$.

The comparison of minimum number of drops for each impeller speed and assumed constant averaged value is presented in Figure 5 for Rushton turbine and high-shear tooth impeller respectively.

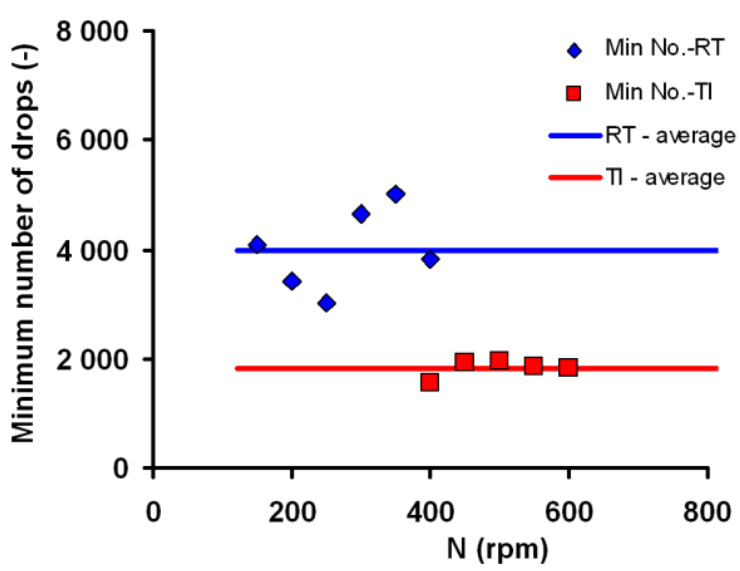

Fig. 5. Minimum number of drops for evaluation - effect of impeller rotational speed.

\subsection{Time evaluation of Sauter mean diameter}

The time evolution of Sauter mean diameter of droplets $d_{p 32}$ was expressed by kinetics models given by Eq. (2). The evaluated kinetics model parameters are presented in Tables 8 and 9 for Rushton turbine and high-shear tooth impeller respectively. The comparison of calculated data and the time course of Sauter mean diameter of droplets $d_{p 32}$ predicted by the kinetics model is presented in dimensionless form in Figures 6 and 7 for Rushton turbine and high-shear tooth impeller respectively.

Table 8. Kinetic model parameters - Rushton turbine

\begin{tabular}{|c|c|c|c|c|c|c|c|}
\hline & & \multicolumn{6}{|c|}{ Rushton turbine } \\
\hline Run \# & & $\begin{array}{c}\text { Impeller speed } \\
N[\mathrm{rpm}]\end{array}$ & $\begin{array}{l}\operatorname{Re} \\
{[-]}\end{array}$ & $\begin{array}{l}W e \\
{[-]}\end{array}$ & $\begin{array}{c}d_{p 32} \\
{[\mathrm{~mm}]}\end{array}$ & $\begin{array}{l}d_{p \max } \\
{[\mathrm{mm}]}\end{array}$ & $\begin{array}{l}k^{*} \\
{[-]}\end{array}$ \\
\hline 1 & & 150 & 26126 & 179 & 0.5336 & 0.6587 & $\mathrm{xxx}$ \\
\hline 1 & $150 \rightarrow 200$ & 200 & 34834 & 317 & 0.4019 & 0.6234 & $3.15 \mathrm{E}-04$ \\
\hline 2 & $200 \rightarrow 250$ & 250 & 43543 & 496 & 0.3191 & 0.4909 & $2.23 \mathrm{E}-04$ \\
\hline 3 & $250 \rightarrow 300$ & 300 & 52251 & 714 & 0.2641 & 04106 & $1.93 \mathrm{E}-04$ \\
\hline 4 & $300 \rightarrow 350$ & 350 & 60960 & 972 & 0.2315 & 0.3510 & $1.68 \mathrm{E}-04$ \\
\hline 5 & $350 \rightarrow 400$ & 400 & 69668 & 1270 & 0.2185 & 0.3097 & $8.11 \mathrm{E}-05$ \\
\hline
\end{tabular}

Table 9. Kinetic model parameters - high-shear tooth impeller

\begin{tabular}{|cc|c|c|c|c|c|c|}
\hline & \multicolumn{9}{|c|}{ high-shear tooth impeller } \\
\hline Run \# & $\begin{array}{c}\text { Impeller speed } \\
N[\mathrm{rpm}]\end{array}$ & $\begin{array}{c}R e \\
{[-]}\end{array}$ & $\begin{array}{c}W e \\
{[-]}\end{array}$ & $\begin{array}{c}d_{p 32} \\
{[\mathrm{~mm}]}\end{array}$ & $\begin{array}{c}d_{p \max } \\
{[\mathrm{mm}]}\end{array}$ & $\begin{array}{c}k^{*} \\
{[-]}\end{array}$ \\
\hline 1 & & 400 & 69668 & 1270 & 0.2968 & 0.4700 & $\mathrm{xxx}$ \\
\hline 1 & $400 \rightarrow 450$ & 450 & 78377 & 1607 & 0.2379 & 0.3834 & $1.06 \mathrm{E}-04$ \\
\hline 2 & $450 \rightarrow 500$ & 500 & 87086 & 1984 & 0.2135 & 0.3468 & $8.28 \mathrm{E}-05$ \\
\hline 3 & $500 \rightarrow 550$ & 550 & 95794 & 2401 & 0.2030 & 0.3190 & $1.07 \mathrm{E}-04$ \\
\hline 4 & $550 \rightarrow 600$ & 600 & 104503 & 2857 & 0.1894 & 0.2969 & $8.88 \mathrm{E}-05$ \\
\hline
\end{tabular}




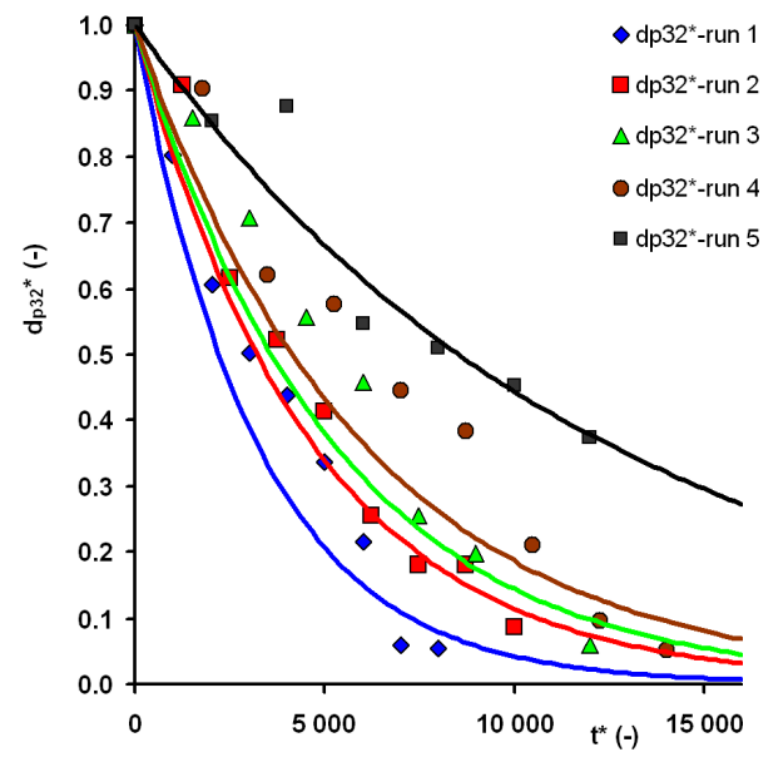

Fig. 6. Time evolution of dimensionless $d_{p 32}$

- Rushton turbine

\subsection{Dimensionless correlations for steady drop sizes}

If the breakup occurs in the inertial subrange, i.e. $\Lambda>d_{p}$ $>\eta_{K}$, drop breakup is controled by inertial forces, hence the drop size $d_{p}$ can be expressed as follows (Hinze [6]):

$$
d_{p} \propto \sigma^{3 / 5} \cdot \rho_{c}^{-3 / 5} \cdot \varepsilon^{-2 / 5}
$$

where $\varepsilon$ is the local turbulent energy dissipation rate, $\rho_{c}$ is the density of continuous phase, $\sigma$ is the interfacial tension between dispersed and continuous phase. In this case the balance between the turbulent forces tending to disrupt a drop and cohesive surface forces holding it together is assumed. Assuming that $\varepsilon \propto N^{3} D^{2}$ the Eq. (3) is rewritten into dimensionless form as follows:

$$
d_{p} / D \propto\left(\rho_{c} \cdot N^{2} \cdot D^{3} / \sigma\right)^{-3 / 5}=W e_{M}^{-3 / 5},
$$

where $W e$ is the impeller Weber number, $N$ is the impeller rotational speed, and $D$ is the impeller diameter. On this basis, the relations for maximum stable drop size $d_{\max }$ are reported (e.g. [7]):

$$
d_{\max } / D=K_{1} \cdot W e_{M}^{-3 / 5},
$$

where $K_{l}$ is the constant of proportionality.

The maximum drop size $d_{\max }$ was estimated from measured drop size distribution as the drop size for which $99 \%$ of the drops are smaller. The Sauter mean drop size and maximum drop size at steady state are presented in Tables 8 and 9 for each experimental run for Rushton turbine and high-shear tooth impeller respectively.

The following correlations were tested for given drop sizes at steady state:

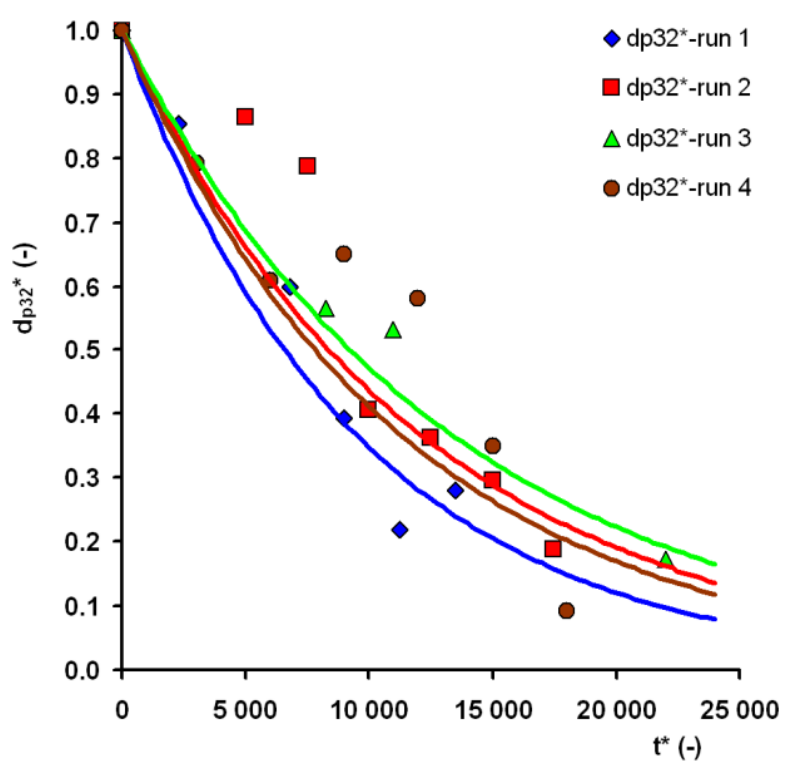

Fig. 7. Time evolution of dimensionless $d_{p 32}$ - high-shear tooth impeller

$$
\begin{aligned}
& d_{p 32} / D=C_{1} \cdot W e_{M}^{-0.6}, \\
& d_{p \max } / D=C_{2} \cdot W e_{M}^{-0.6,}
\end{aligned}
$$

where $C_{1}$ and $C_{2}$ are constants of proportionality. The tested correlations given by Eqs. (6) and (7) predict the constant ratio between Sauter mean diameter $d_{p 32}$ and maximum drop size $d_{p \max }$ as it follows (e.g. [8]):

$$
d_{p \max } / d_{p 32}=C_{2} / C_{1}=C_{3}
$$

The predicted correlations were tested by hypothesis testing [4]. The experimental point for impeller speed $N$ $=400 \mathrm{rpm}$ was excluded from testing for $d_{\text {pmax }} / D$ ratio for Rushton turbine, because out of trend. The excluded experimental point is presented in the graph for completeness. The hypothesis test results are presented in Tables 10 and 11 for Rushton turbine and high-shear tooth impeller respectively. For illustration, the values of calculated $|t|$ value are presented here also.

For Rushton turbine, the predicted correlations for $d_{p 32} / D$ and $d_{p \max } / D$ ratio were not statistically confirmed. However, as it can be seen in Table 10, the exponents for these ratios obtained from the experimental data are close to the expected value -0.6. Moreover, the correlation index is very close to 1 , which indicates that the experimental data are well-connected to the expected trend line. For these reasons it was decided to plot the for $d_{p 32} / D$ and $d_{p \max } / D$ ratio with Weber number exponent $n$ $=0.6$ (Fig. 8). The ratio of $d_{p \max } / d_{p 32}$ was found to be statistically independent of the impeller Weber number (Fig. 10). 
Table 10. Dimensionless correlations - hypothesis testing; Rushton turbine

\begin{tabular}{|l|c|c|c|c|}
\hline \multicolumn{1}{|c|}{ Hypothesis testing } & $d_{p 32} / D[-]$ & $d_{p \max } / D[-]$ & $d_{p \max } / d_{p 32}[-]$ & $k^{*}[-]$ \\
\hline & & & & -0.845 \\
\hline Relation: $\beta_{\text {calc }}(-)$ & -0.471 & -0.504 & 0.061 & -0.6 \\
Hypothesis: $\beta_{\text {pred }}(-)$ & -0.6 & -0.6 & 0 & 1.2 \\
t-characteristics $|t|$ & 6.3 & 14.9 & 1.1 & 3.1825 \\
Critical t-characteristics & 2.7764 & 3.1825 & 2.7764 & Acceptable \\
Hypothesis: & Not acceptable & Not acceptable & Acceptable & \\
\hline
\end{tabular}

Note: Hypothesis testing: property $=\mathrm{B}_{\mathrm{R}} \cdot(\mathrm{We})^{\text {Bcalc }}$, hypothesis tested: property $=\mathrm{B}_{\mathrm{H}} \cdot(\mathrm{We})^{-0.6}$.

Table 11. Dimensionless correlations - hypothesis testing; high-shear tooth impeller

\begin{tabular}{|l|c|c|c|c|}
\hline \multicolumn{1}{|c|}{ Hypothesis testing } & $d_{p 32} / D[-]$ & $d_{p \max } / D[-]$ & $d_{p \max } / d_{p 32}[-]$ & $k^{*}[-]$ \\
\hline Relation: $\beta_{\text {calc }}(-)$ & & & & -0.344 \\
Hypothesis: $\beta_{\text {pred }}(-)$ & -0.530 & -0.550 & -0.020 & -0.6 \\
t-characteristics $|t|$ & -0.6 & -0.6 & 0 & 0.8 \\
Critical t-characteristics & 0.9 & 0.9 & 0.8 & 4.3027 \\
Hypothesis: & 3.1825 & 3.1825 & 3.1825 & acceptable \\
\hline
\end{tabular}

Note: Hypothesis testing: property $=\mathrm{B}_{\mathrm{R}} \cdot(\mathrm{We})^{\text {Bcalc }}$, hypothesis tested: property $=\mathrm{B}_{\mathrm{H}} \cdot(\mathrm{We})^{-0.6}$.

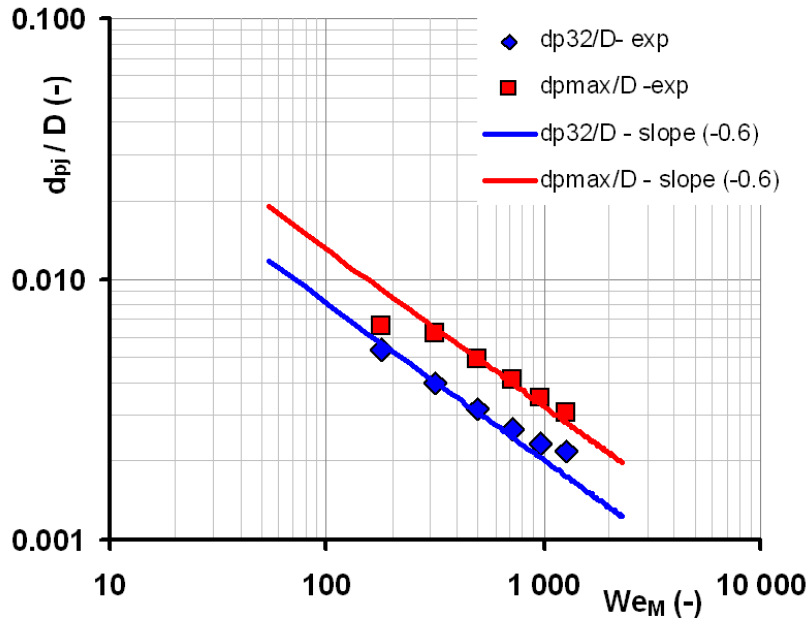

Fig. 8. Dimensionless correlations for ratios $d_{p 32} / D$ and $d_{p \max } / D$ - Rushton turbine.

Thus, the following correlations were evaluated for Rushton turbine:

$$
\begin{aligned}
& d_{p 32} / D=0.1277 \cdot W e_{M}^{-0.6} \quad(\mathrm{R}=0.971), \\
& d_{p \max } / D=0.2056 \cdot W e_{M}^{-0.6} \quad(\mathrm{R}=0.984), \\
& d_{p \max } / d_{p 32}=1.516 .
\end{aligned}
$$

For high-shear tooth impeller, the predicted correlations for $d_{p 32} / D$ and $d_{p \max } / D$ ratio were not statistically confirmed. However, as it can be seen in Table 10, the exponents for these ratios obtained from the experimental data are close to the expected value 0.6. Moreover, the correlation index is very close to 1 ,

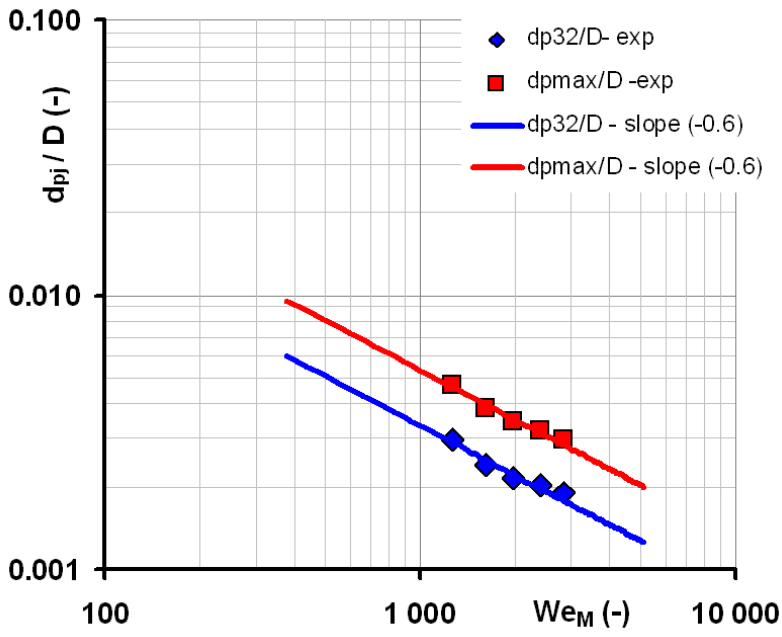

Fig. 9. Dimensionless correlations for ratios $d_{p 32} / D$ and $d_{p \max } / D$ - high-shear tooth impeller.

which indicates that the experimental data are wellconnected to the expected trend line. For these reasons, although the predicted dependence was not statistically confirmed, it was decided to plot the for $d_{p 32} / D$ and $d_{\text {max }} / D$ ratio with Weber number exponent $n=0.6$ (Fig. 9). The ratio of $d_{p \max } / d_{p 32}$ was found to be statistically independent of the impeller Weber number (Fig. 10).

Thus, the following correlations were evaluated for high-shear tooth impeller:

$$
\begin{aligned}
& d_{p 32} / D=0.2109 \cdot W e_{M}^{-0.6} \quad(\mathrm{R}=0.967), \\
& d_{p \max } / D=0.3360 \cdot W e_{M}^{-0.6} \quad(\mathrm{R}=0.983), \\
& d_{p \max } / d_{p 32}=1.592 .
\end{aligned}
$$




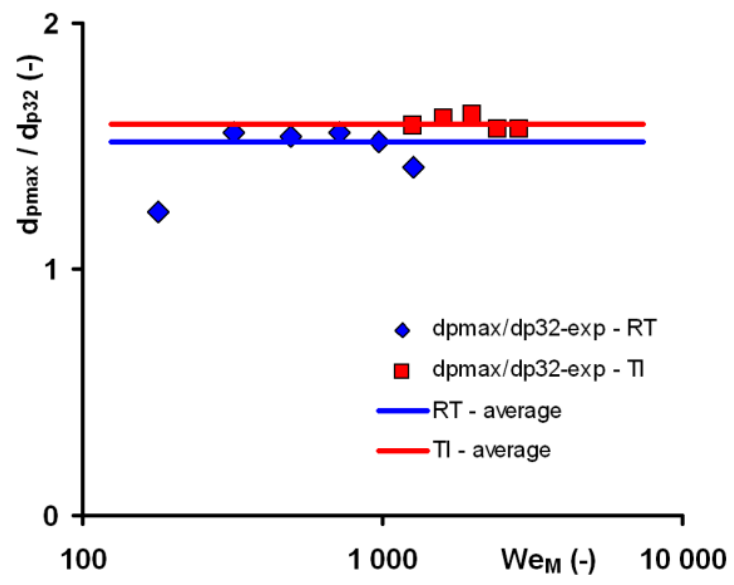

Fig. 10. Dimensionless correlation $d_{p \max } / d_{p 32}$.

\subsection{Dimensionless correlation for breaking-rate constant}

We assumed speculatively that the dimensionless breaking - rate constant $k^{*}$ depends on We number as follows:

$$
k^{*}=C_{4} \cdot W e_{M}^{-0.6},
$$

The assumed dependence was statistically confirmed both for Rushton turbine and high-shear tooth impeller. The $k^{*}$-values for impeller speeds $\mathrm{N}=150 \mathrm{rpm}$ and 400 rpm were excluded from testing for Rushton turbine and high-shear tooth impeller respectively. The hypothesis test results are presented in Tables 10 and 11. Thus, the following relations were evaluated:

a) for Rushton turbine:

$$
k_{R T}^{*}=9.53 E-03 \cdot W e_{M}^{-0.6} \quad(\mathrm{R}=0.946),
$$

b) for tooth impeller:

$$
k_{T I}^{*}=8.70 E-03 \cdot W_{M}{ }^{-0.6} \quad(\mathrm{R}=0.548),
$$

For high-shear tooth impeller, the power-law exponent is relatively far from expected value ( -0.344 vs. -0.6) and correlation index is far from the value 1 for expected exponent of -0.6 . Despite of this, the assumed trend line is statistically acceptable. It was found that the constants of proportionality of Eqs. (16) and (17) are close to each other. Therefore, we treated the all $k^{*}$ values for both impellers together. In this case powerlaw exponent $\beta_{\text {calc }}=-0.667$ and $t$-characteristics $=0.7$ were evalutated by hypothesis testing. Thus, the following relation was obtained:

$$
k_{R T-T I}^{*}=9.41 E-03 \cdot W e_{M}^{-0.6} \quad(\mathrm{R}=0.967),
$$

The comparison of this correlation and treated $k^{*}$ values is presented in Fig. 11.

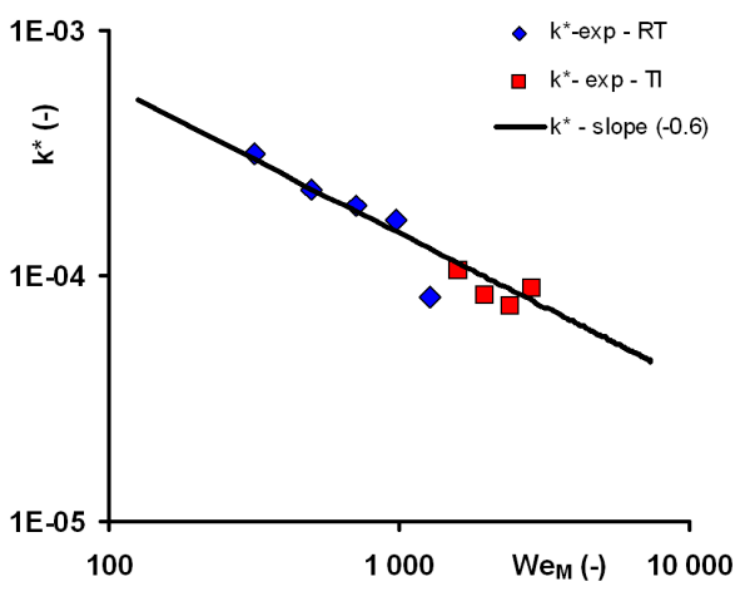

Fig. 11. Dimensionless breaking-rate constant vs. Weber number

\section{Conclusions}

The following results have been obtained in this study:

The time evolution of DSD was investigated in baffled tank agitated by Rushton turbine and high-shear impeller for liquid-liquid dispersion. The tests have been carried out at the silicone oil - water dispersion (oil in water) of dispersion fraction 0.00047 . In this case no coalescence occurs. The drop sizes were determined by image analysis.

The calibration tests were carried out to obtain the ratio between the real dimensions of the particles and the pixels detected by image analysis. For calibration the special polymeric spheres "Nylon 6/6 Balls" of precise diameter were used.

The minimum number of drops that is necessary to evaluate was determined for each impeller rotational speed for both tested impellers. On the basis of the hypothesis test, it was found that the minimum number of drops can be statistically taken as constant and independent of the impeller rotational speed for both impellers tested. It has been found that the minimum number of drops that must be treated to obtain relevant data is 4000 and 1830 for Rushton turbine and highshear tooth impeller respectively.

The time evolution of Sauter mean diameter of droplets $d_{p 32}$ was expressed by kinetics models proposed by Sulc et al. [3]

The following correlations predicted by the Kolmogorov-Hinze theory were evaluated at steady state: $d_{p 32} / D=\mathrm{C}_{1} \cdot W e_{M}^{-0.6}$ and $d_{p \max } / D=\mathrm{C}_{2} \cdot W e_{M}{ }^{-0.6}$, where $W e_{M}$ is the impeller Weber number.

The ratio of $d_{p \max } / d_{p 32}$ was found to be statistically independent of the impeller Weber number for both impellers.

The dimensionless breaking rate constant $k^{*}$ was found to be proportional to $W e_{M}{ }^{-0.6}$.

This research has been supported by Grant Agency of the Czech Republic project No. 16-20175S and by Ministry of Education, Youth and Sports of the Czech Republic project No. RVO:67985874. 


\section{Symbols}

B baffle width, $m$

C impeller clearance, $m$

$d_{p} \quad$ drop size diameter, $m$

$\mathrm{d}_{\text {pmax }}$ maximum drop size, $\mathrm{m}$

$\mathrm{d}_{\mathrm{p} 32}$ Sauter mean diameter, $\mathrm{m}$

D impeller diameter, $\mathrm{m}$

$\mathrm{H}$ liquid height, $\mathrm{m}$

$\mathrm{k}$ breaking-rate constant, $\mathrm{s}^{-1}$

$\mathrm{k}^{*} \quad$ dimensionless breaking-rate constant, -

$\mathrm{m}$ number of experimental points, -

$\mathrm{N}$ impeller rotational speed, $1 / \mathrm{s}$

Re impeller Reynolds number; $\operatorname{Re}=N \cdot D^{2} / v,-$

$\mathrm{t}$ time, $\mathrm{s}$

$t_{(m-2), a=0.05} t$-distribution for $(m-2)$ degrees of freedom and significance level $\alpha$, -

$\mathrm{T}$ tank diameter, $\mathrm{m}$

$\mathrm{We}_{\mathrm{M}}$ impeller Weber number; $\mathrm{We}=\rho_{\mathrm{c}} \cdot \mathrm{N}^{2} \cdot \mathrm{D}^{3} / \sigma,-$

\section{Greek letters}

$\eta_{\mathrm{K}} \quad$ Kolmogorov length scale, $\mathrm{m}$

$\varphi \quad$ volume fraction of dispersed phase, -

$v$ kinematic viscosity, $\mathrm{m}^{2} / \mathrm{s}$

$\rho_{c} \quad$ density of continuous phase, $\mathrm{kg} / \mathrm{m}^{3}$

$\sigma \quad$ interfacial tension, $\mathrm{N} / \mathrm{m}$

$\Lambda$ integral length scale, $m$

\section{References}

1. S.L. Yeoh, G. Papadakis, M. Yianneskis, Chem. Eng. Sci., 60, 2293-2302 (2005)

2. D. Cheng, X. Feng, J. Cheng, Ch. Yang, Chem. Eng. Sci., 101, 272-282 (2013)

3. R. Šulc, B. Kysela, P. Ditl, Chem. Papers, 72, 543553 (2018)

4. B. Kysela, J. Konfršt, Z. Chára, R. Šulc, P. Ditl, Insitu measurement of particle size distribution in an agitated vessel. In: Proceedings of $18^{\text {th }}$ International Conference Transport \& Sedimentation of solid particles. Prague, Czech Republic, 2017

5. B.L. Bowerman, R.T.O'Connell, Applied statistics: improving business processes (Richard D. Irwin, USA, 1997)

6. J.O. Hinze, AIChE J., 1, 289-295 (1955)

7. A.W. Pacek, C.C. Man, A.W. Nienow, Chem. Eng. Sci., 53, 2005-2011 (1998)

8. R.V. Calabrese, T.P.K. Chang, P.T. Dang, AIChE J., 32, 657-666 (1986) 